\title{
Article \\ A Trilaminar-Catalytic Layered MEA Structure for a Passive Micro-Direct Methanol Fuel Cell
}

\author{
Huichao Deng ${ }^{1}$, Jiaxu Zhou ${ }^{1, *}$ and Yufeng Zhang ${ }^{2}$ \\ 1 School of Mechanical Engineering and Automation, Beihang University, Beijing 100191, China; \\ denghuichao@buaa.edu.cn \\ 2 MEMS Center, Harbin Institute of Technology, Harbin 150001, China; yufeng_zhang@hit.edu.cn \\ * Correspondence: Jiaxuzhou@buaa.edu.cn; Tel.: +86-010-8233-9055
}

Citation: Deng, H.; Zhou, J.; Zhang, Y. A Trilaminar-Catalytic Layered MEA Structure for a Passive Micro-Direct Methanol Fuel Cell. Micromachines 2021, 12, 381. https:// doi.org $/ 10.3390 / \mathrm{mi1} 2040381$

Academic Editors: Jinyuan Qian, Zan Wu, Junhui Zhang and Bengt Sunden

Received: 5 March 2021

Accepted: 27 March 2021

Published: 1 April 2021

Publisher's Note: MDPI stays neutral with regard to jurisdictional claims in published maps and institutional affiliations.

Copyright: (C) 2021 by the authors. Licensee MDPI, Basel, Switzerland. This article is an open access article distributed under the terms and conditions of the Creative Commons Attribution (CC BY) license (https:/ / creativecommons.org/licenses/by/ $4.0 /)$.

\begin{abstract}
A membrane electrode assembly (MEA) with a novel trilaminar-catalytic layered structure was designed and fabricated for a micro-direct methanol fuel cell ( $\mu$-DMFC). The trilaminar-catalytic layer comprises three porous layers. The medial layer has a lower porosity than the inner and outer layers. The simulation results predicted a lower water content and a higher oxygen concentration in the trilaminar-catalytic layer. The novel trilaminar-catalytic layer enhanced the back diffusion of water from the cathode to the anode, which reduces methanol crossover and improves oxygen mass transportation. The electrochemical results of the half-cell test indicate that the novel MEA has a greatly increased cathode polarization and a slightly increased anode polarization. Thus, this novel $\mu$-DMFC structure has a higher power density and a longer discharging time, and hence may be used in portable systems.
\end{abstract}

Keywords: micro-direct methanol fuel cell; trilaminar-catalytic; water management; methanol crossover

\section{Introduction}

Due to the advantages conferred by their high energy density, facility of operations, fuel storage, and lack of pollution, proton exchange membrane fuel cells have been proposed as power sources for portable applications, automobiles, and stationary power plants [1-3]. The direct methanol fuel cell (DMFC) in the proton exchange membrane fuel cell provides greater advantages in portable applications and has attracted more attention in academia and industry [4-6]. This fuel cell uses liquid methanol as fuel. Compared with hydrogen, liquid methanol has many advantages, such as being easy to obtain, low cost, and having low storage and transport requirements. Many studies focused on the use of direct methanol fuel cells. A four-cell modular passive DMFC stack was designed, fabricated, and tested previously. A multi-module stack and DC-DC converter were combined to power an experimental fan and charge a mobile phone [7], while a passive direct methanol fuel cell, acting as transducer of an electrochemical sensor, was used to the detect of carcinoembryonic antigen [8]. Part of the reason for the success of these applications is that fuel cells provide several times more energy than batteries. With the increasing demand for portable energy, micro-direct methanol fuel cells ( $\mu$-DMFCs) are becoming a promising power source in the fuel cell family.

However, related research demonstrates that the performance of current $\mu$-DMFCs is far below the expected theoretical values [9]. Thus, it is important to study the mass transfer characteristics, reaction mechanism, and characteristic parameters of these cells as it may help to improve our understanding of the internal mass transfer and the electrochemical reaction mechanism within $\mu$-DMFCs. These studies will provide rationales for the optimization of the structure and performance of future $\mu$-DMFCs. The crucial factor restricting the output performance of traditional $\mu$-DMFCs is the low efficiency of the mass transport of oxygen at the cathode, often resulting from water flooding the cathode surface. At present, researchers are primarily focused on the water back diffusion from the 
cathode to the anode, as this can potentially solve the flooding at the cathode and decrease methanol crossover. A new hybrid catalyst layer (CL) was described in reference [10], wherein relatively hydrophilic and hydrophobic CLs were combined to form a hybrid catalyst layer. The relatively hydrophobic CLs were designed using hydrophobic binder polytetrafluoroethylene (PTFE), and the relatively hydrophilic CLs were designed using the hydrophilic binder Nafion.

Experimental results indicated that the hydrophilic and hydrophobic control of CLs can effectively produce better methanol and water concentration distribution. A new cathode micro-porous layer (MPL) was proposed with fluorinated carbon nanotubes [11]. The experiment results showed that the new microporous layer was free of cracks and had super hydrophobicity. Under the neat methanol operating conditions of passive direct methanol fuel cells, the water recovery flux significantly increased, improving the performance of the cell. A three-dimensional graphene framework was used for the first time to manufacture cathode MPL for enhancing water management [12]. The intrinsic pore structure and characteristics of the graphene frame can increase the hydraulic pressure of the cathode CLs, thus enhancing the water back diffusion from cathode to anode and improving the mass transfer of the cathode. The experimental results showed that the performance and stability of the prepared cells were improved remarkably. Reduced graphene oxide deposited in stainless steel fiber felt (SSFF) as a gas diffusion layer (GDL) was applied to a micro-direct methanol fuel cell [13]. This enhanced the back diffusion of water while reducing the anodic methanol crossover. The experimental results showed that the cell at $4 \mathrm{M}$ and $5 \mathrm{M}$ methanol concentration with the new diffusion layer performed better than a conventional cell.

From the literature review, water back diffusion enhancement is an effective method for water management, preventing flooding in the cathode and lowering the methanol crossover from the anode to the cathode. Although significant advancements have been achieved using the aforementioned methods, the oxygen mass transport within the catalyst layer is still a problem. In this study, we examined whether a trilaminar-catalytic layered membrane electrode assembly (MEA) structure could facilitate the increase in water back diffusion and promote oxygen mass transportation. The trilaminar-catalytic layer comprises an inner, medial, and outer layer. The medial layer has lower porosity than the inner and outer layers. This creates a water pressure gradient between the inner and medial layers, and an oxygen concentration gradient between the outer and medial layers. Thus, the trilaminar-catalytic layered MEA can enhance water back diffusion from the cathode to the anode, as well as oxygen mass transportation, by creating beneficial gradients.

\section{Simulation Analysis}

To effectively validate the trilaminar-catalytic layered cathode structure, a threedimensional static model was characterized and simulated using a two-phase thermal model for a passive DMFC [14,15]. For simplification and improved results, the region simulated included three cathode catalyst layers, each with a different porosity. The porosity of middle layer was set to $0.4[16,17]$ and the porosity of the other layers was set to 0.7. The simplified two-dimensional modeling domain of the DMFC is shown in Figure 1. This model was simulated under the following simplifications and assumptions:

(1) The fuel cell works under steady-state and isothermal conditions.

(2) The fuel cell and environment have thermal isolation so that the heat does not disperse from the gas diffusion layer (GDL) into the environment.

(3) The concentration change in methanol does not influence the cathode.

(4) The boundary condition of the left line is Nafion membrane, and the boundary condition of the right line is cathode GDL. 


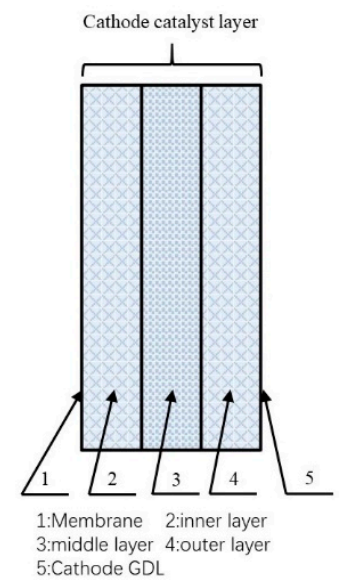

Figure 1. The modeling domain.

The coagulum model was used to describe the electrode reaction of the catalyst layer. The coagulum included the catalyst and the embedded polymer electrode carbon atoms. This model equation evolved from the analytical solutions for spherical porous particle diffusion reactions. The potential distribution under a DC conductive medium is described as follows:

$$
\begin{gathered}
\nabla \cdot\left(-\kappa_{m, e f f} \nabla \phi_{m}\right)=0, \\
\nabla \cdot\left(-\kappa_{s, e f f} \nabla \phi_{s}\right)=0,
\end{gathered}
$$

where $\phi_{s}$ is the potential of the membrane, $\phi_{m}$ is the potential of the cathode, $\kappa_{s, e f f}$ is the solid effective electronic conductivity, and $\kappa_{m, e f f}$ is the membrane ionic conductivity. The coagulum model indicated the current density of the catalytic layer, which comprised ion conductive materials and parts attached to the catalyst's electronic conductive particles. The coagulum, which had a constant electronic and ionic potential, was analytically expressed as the local current density, through the diffusion kinetics equation and through the kinetic equation of the electrode process (Butler-Volmer equation) [18]. The cathode current density equation was formulated as follows:

$$
\begin{gathered}
j_{a g g, c}=-6 n_{c} F\left(\frac{D_{a g g}}{R_{a g g}^{2}}\right)\left(1-\lambda_{c} \operatorname{coth} \lambda_{c}\right) \beta_{c}, \\
\lambda_{c}=\sqrt{\frac{i_{0 c} S R_{a g g}^{2}}{4 F c_{\mathrm{O}_{2}, r e f} D_{a g g}} \exp \left(-\frac{F}{2 R T} \eta_{c}\right),} \\
\beta_{c}=c_{\mathrm{O}_{2}, a g g} \\
\eta_{c}=\phi_{s}-\phi_{m}-E_{e q, c},
\end{gathered}
$$

where $D_{a g g}$ is the coagulum gas diffusion coefficient $\left(\mathrm{m}^{2} / \mathrm{s}\right), R_{a g g}$ is the coagulum radius, $n_{c}$ is the charge transfer coefficient (which is -2 ), $S$ is the specific area of catalytic material in coagulum, $F$ is the Faraday constant $(\mathrm{C} / \mathrm{mol}), R$ is the gas constant, $T$ is the temperature $(\mathrm{K}), c_{i, r e f}$ is the reference substance concentration $\left(\mathrm{mol} / \mathrm{m}^{3}\right), c_{i, a g g}$ is the coagulum surface corresponding concentration $\left(\mathrm{mol} / \mathrm{m}^{3}\right), i_{0 c}$ is the exchange current density $\left(\mathrm{A} / \mathrm{m}^{2}\right)$, and $E_{e q, c}$ is the balance voltage.

The reactive gas was considered to be an ideal gas transferred by diffusion and convection, while the electrode was assumed to be an isotropic porous medium with uniform morphological characteristics, such as porosity and permeability. The gas in the electrode was a continuous phase, so Darcy's law proved that the pressure gradient, the 
viscosity of the fluid, and the porous medium structure determined the water velocity, $\boldsymbol{u}_{l}$, within the porous medium:

$$
\boldsymbol{u}_{l}=-\frac{K k_{r l}}{\mu_{l}} \nabla p_{l}
$$

where $K$ is the absolute permeability of the porous medium, $k_{r l}$ is the relative permeability of the liquid phase, $\boldsymbol{u}_{l}$ is the dynamic viscosity of the liquid phase, and $p_{l}$ is the pressure of the liquid phase. In the cathode boundary, the electrochemical reaction rate and gas flow velocity were calculated from the total mass flow, according to Equation (8).

$$
-\left.\boldsymbol{n} \cdot \boldsymbol{u}\right|_{\text {cathode }}=-\frac{j_{\text {cathode }}}{\rho F}\left[\frac{M_{\mathrm{O}_{2}}}{4}+\left(\frac{1}{2}+\lambda_{\mathrm{H}_{2} \mathrm{O}}\right) M_{\mathrm{H}_{2} \mathrm{O}}\right],
$$

where $\lambda_{\mathrm{H}_{2} \mathrm{O}}$ is the electro-osmotic drag coefficient of water; the above model considers the three substances in the cathode: oxygen, water, and nitrogen.

The Maxwell-Stefan multicomponent diffusion was determined by the following Equation (9):

$$
\frac{\partial}{\partial t} \rho \omega_{i}+\nabla \cdot\left[-\rho \omega_{i} \sum_{j=1}^{N} D_{i j}\left\{\frac{M}{M_{j}}\left(\nabla \omega_{j}+\omega_{j} \frac{\nabla M}{M}\right)+\left(x_{j}-\omega_{j}\right) \frac{\nabla p}{p}\right\}+\omega_{i} \rho \boldsymbol{u}+D_{i}^{T} \frac{\nabla T}{T}\right]=R_{i} .
$$

The software calculated the mass fraction of the solution $\omega_{i}$. The proton exchange membrane fuel cell model assumed that the temperature-driven diffusion was not obvious, and that the source term $\mathrm{R}$ was set to 0 . For the three types of gases in cathode (oxygen indicated by 1 , water by 2 , and nitrogen by 3 ), the mass transfer could be simulated using the following equations, which determined the flow rate together with Darcy's law:

$$
\begin{gathered}
\nabla \cdot\left\{-\rho \omega_{1} \sum_{j}\left[D_{1 j}>\left(\nabla x_{j}+\left(x_{j}-\omega_{j}\right) \frac{\nabla p}{p}>\right)\right]\right\}=-\left(\rho \boldsymbol{u} \cdot \nabla \omega_{1}\right), \\
\nabla \cdot\left\{-\rho \omega_{2} \sum_{j}\left[D_{1 j}>\left(\nabla x_{j}+\left(x_{j}-\omega_{j}\right) \frac{\nabla p}{p}>\right)\right]\right\}=-\left(\rho \boldsymbol{u} \cdot \nabla \omega_{2}\right), \\
\boldsymbol{\omega}_{3}=\mathbf{1}-\boldsymbol{\omega}_{1}-\boldsymbol{\omega}_{2}
\end{gathered}
$$

where $p$ is the pressure $(\mathrm{Pa}), T$ is the temperature $(\mathrm{K})$, and $u$ is the velocity $(\mathrm{m} / \mathrm{s})$. At the junction of the electrode and the membrane, the mass flux of oxygen and water in the cathode is determined by the electrochemical reaction rate:

$$
\begin{gathered}
-\left.n \cdot \mathbf{N}_{\mathrm{O}_{2}}\right|_{\text {cathode }}=-\frac{j_{\text {cathode }}}{4 F} M_{\mathrm{O}_{2}} \\
-\left.\boldsymbol{n} \cdot \mathbf{N}_{\mathrm{H}_{2} \mathrm{O}}\right|_{\text {cathode }}=-\frac{j_{\text {cathode }}}{F}\left(\frac{1}{2}+\lambda_{\mathrm{H}_{2} \mathrm{O}}\right) M_{\mathrm{H}_{2 \mathrm{O}}} .
\end{gathered}
$$

The coupled equations were numerically calculated by the finite element method using COMSOL Multiphysics 5.5. We used a physics-controlled mesh to automate meshing. The finer element size was selected reasonably, and the number of elements was 11,466. The temperature over the entire solution domain was set at a constant value of $298 \mathrm{~K}$. Figure 2 shows the comparison of water mass fraction between the traditional catalyst layer and the trilaminar-catalytic layer. The traditional catalyst layer was divided into three layers, all of which had the same porosity. The trilaminar-catalytic layer comprised the inner, medial, and outer layers. In both cases, the water mass fraction of the catalyst layer remained between $37 \%$ and $38 \%$. The water was not only generated by the chemical reaction in the catalyst layer, but also penetrated from the anode through the proton exchange membrane. The water content increased from the outer to the inner catalytic layers, which was similar to, yet more pronounced than, the behavior at the proton exchange membrane. Too much water content at the cathode inhibited the reaction and resulted in the flooding of the 
cathode, which was detrimental to the stability of the battery output performance, and thus may have lowered the long-term output performance. However, the reaction at the anode required the water's participation, so it was more beneficial to allow water back diffusion from the cathode to the anode, and to use the proton exchange membrane to improve the performance of the $\mu$-DMFC.

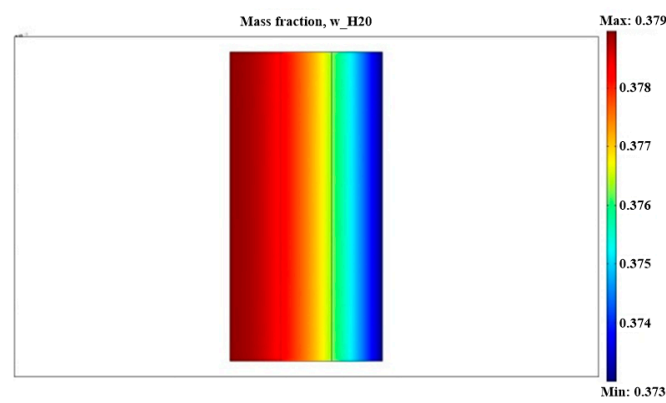

(a)

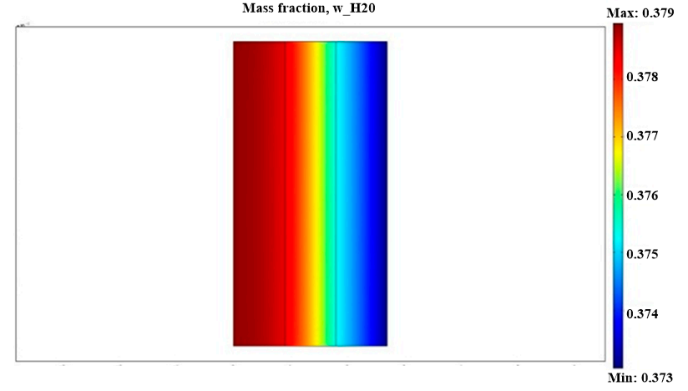

(b)

Figure 2. Comparison of water mass fraction in the traditional catalyst layer and trilaminar-catalytic layer: (a) traditional catalyst layer; (b) trilaminar-catalytic layer.

According to the simulation results, the water content in the inner layer of the trilaminar-catalytic layer was higher than that of the traditional catalytic layer. Furthermore, the water content in the middle and outer layers of the trilaminar-catalytic layer were lower than that of the traditional catalytic layer. This was due to the variation in porosity. In the trilaminar-catalytic layer, the porosity of the inner layer was 0.7 , which is higher than that of the middle layer, at 0.4 . The water diffusion was blocked by the middle layer, which increased the hydraulic pressure in the catalyst layer and improved the water back diffusion from the cathode to anode. The porosity of the middle layer when compared to the outer layer was lower. Therefore, the water generated by the reaction was more easily discharged through the pores of the outer layer. Due to the lower water pressure, the gas diffusion mass transfer ability improved and the cell output performance increased.

Figure 3 compares the oxygen mass fraction in the traditional catalyst layer with that of the trilaminar-catalyst layer. As can be seen from the results of these two simulations, the oxygen mass fraction in the middle and outer layers of the trilaminar-catalytic layer was higher than that of the traditional catalytic layer. From the outer layer to the inner layer, the oxygen content and the reaction rate decreased gradually. When comparing these two conditions, the structure of the trilaminar-catalytic layer, with its differing porosity, produced superior performance. As the outer porosity of the catalyst layer was larger (0.7), gas transfer was easier, which resulted in more oxygen reaching the middle layer of the catalyst layer, promoting the chemical reaction.

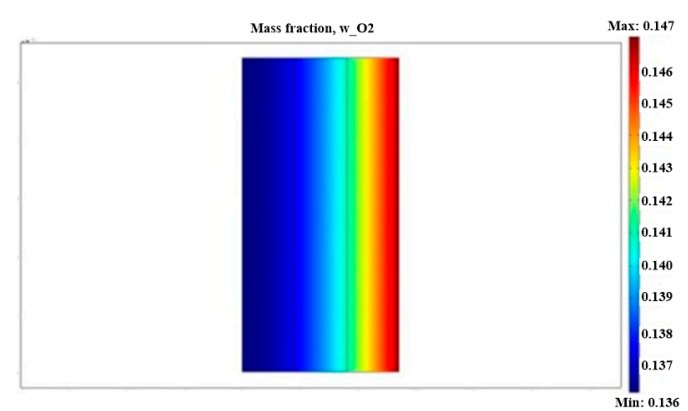

(a)

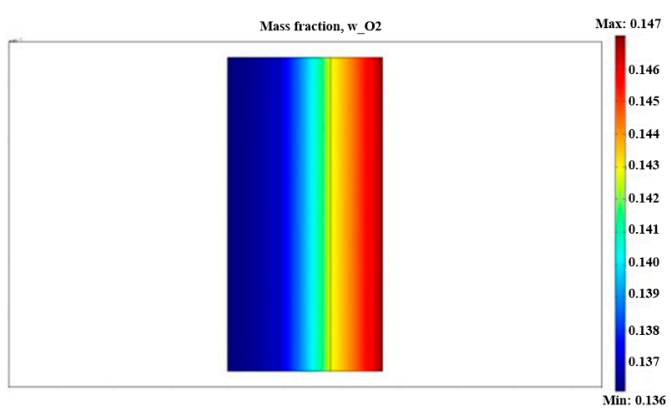

(b)

Figure 3. Comparison of oxygen mass fraction in the traditional catalyst layer and trilaminar-catalytic layer: (a) traditional catalyst layer; (b) trilaminar-catalytic layer. 


\section{Fabrication and Assembly Results}

A mixture of $90 \mathrm{wt} \%$ XC-72 and $10 \mathrm{wt} \%$ PTFE was sprayed onto the surface of carbon paper that served as a microporous layer, with a carbon loading of $4 \mathrm{mg} \mathrm{cm}^{-2}$. The anode catalyst inks (comprising $40 \mathrm{wt} \% \mathrm{Pt}-\mathrm{Ru} / \mathrm{C}, 5 \mathrm{wt} \%$ solubilized Nafion, isopropanol, and deionized water in 1:1 (v:v) were uniformly sprayed using a spray gun onto the GDL with a catalyst loading of approximately $8.33 \mathrm{mg} \mathrm{cm}^{-2}$. Cathode catalyst ink A comprised $40 \mathrm{wt} \% \mathrm{Pt} / \mathrm{C}, 5 \mathrm{wt} \%$ solubilized Nafion, isopropanol and deionized water in 1:1 (v:v). Cathode catalyst ink B was prepared by mixing $25 \mathrm{wt} \%$ pore-former $(\mathrm{PF}) \mathrm{NH}_{4} \mathrm{HCO}_{3}$ into ink $A$. The cathode gas diffusion electrodes (GDEs) were made by separately spraying ink $A$ and ink $B$ over the microporous treated carbon paper, with a catalyst loading of $6.25 \mathrm{mg} \mathrm{cm}^{-2}$; these are referred to as the no PF cathode and the full PF cathode. The trilaminar-catalytic layered cathode GDE, called the partial PF cathode, was constructed by spraying ink $B$ over the microporous treated carbon paper with a catalyst loading of approximately $2.09 \mathrm{mg} \mathrm{cm}^{-2}$ (outer layer), then by spraying ink A, increasing catalyst loading to approximately $4.18 \mathrm{mg} \mathrm{cm}^{-2}$ (middle layer), and finally by spraying ink $\mathrm{B}$, increasing catalyst loading to approximately $6.25 \mathrm{mg} \mathrm{cm}^{-2}$ (inner layer). The Nafion membrane was pretreated in water baths of deionized water, $3 \mathrm{wt} \% \mathrm{H}_{2} \mathrm{O}_{2}$, and $3 \mathrm{wt} \%$ $\mathrm{H}_{2} \mathrm{SO}_{4}$ for $1 \mathrm{~h}$ at $353 \mathrm{~K}$. The Nafion membrane was sandwiched between two GDEs and hot pressed under $4 \mathrm{MPa}$ at $303 \mathrm{~K}$ for $120 \mathrm{~s}$ to fabricate a 5-layer MEA with an active area of $1.15 \times 1.15 \mathrm{~cm}$. Thus, the MEA was completely assembled as shown in Figure 4a. The partial PF cathode scanning electron microscope image (SEM) [19-21] is shown in Figure $4 b$.

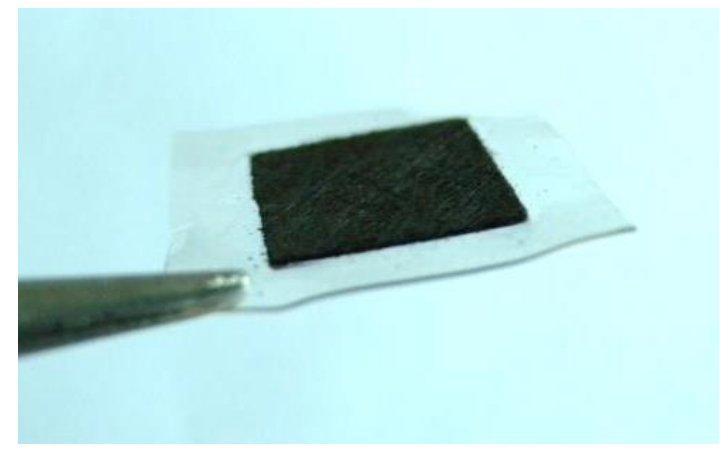

(a)

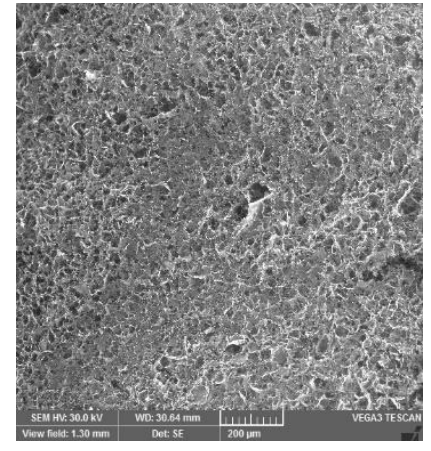

(b)

Figure 4. Picture of the passive micro-direct methanol fuel cell ( $\mu$-DMFC) with the trilaminar-catalytic layer structure: (a) Photograph of the membrane electrode assembly (MEA) with the trilaminar-catalytic layer; (b) partial pore former (PF) cathode scanning electron microscope image (SEM).

The passive $\mu$-DMFC had anode parallel channels [22] with an open ratio of $50 \%$. The microchannel had a width equal to $0.83 \mathrm{~mm}$, and the channel length was equal to $10 \mathrm{~mm}$. The cathode current collector had self-breathing openings with an open ratio of $37 \%$. The hole diameter was $1.32 \mathrm{~mm}$. Stainless steel plates with a thickness of $300 \mu \mathrm{m}$ were chosen to fabricate the anode and cathode current collectors. A $500 \mathrm{~nm}$ layer of Au was deposited on the current collectors by a magnetron sputtering ion plating (MSIP) to reduce contact resistance and to avoid chemical corrosion. To complete the assembly, two fixtures with current collectors and the other components were clamped together using four screws. Outside the anode collector plate was a $2.5 \mathrm{~mL}$ methanol solution storage chamber. The picture of the passive $\mu$-DMFC after assembly is shown in Figure 5. 


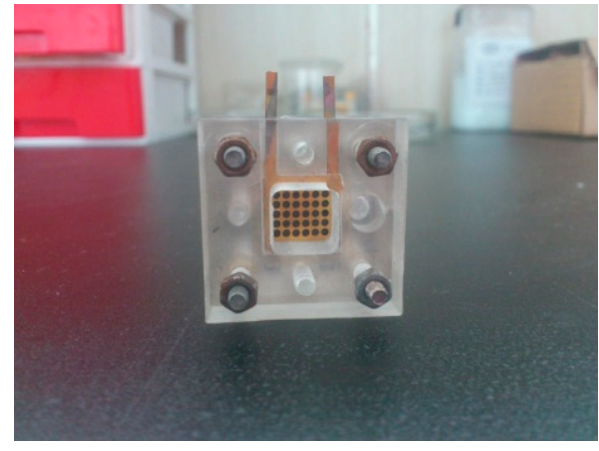

(a)

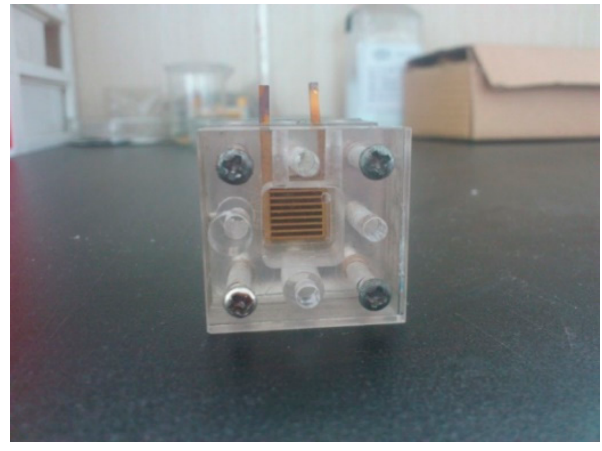

(b)

Figure 5. Photograph of the assembled $\mu$-DMFC: (a) photograph of the MEA with trilaminar-catalytic layer; (b) partial PF cathode scanning electron microscope image (SEM).

\section{Result and Discussion}

To analyze the influence of the trilaminar-catalytic layered cathode on the performance of $\mu$-DMFC, the experiments were passively fed with a $2.5 \mathrm{~mL}$ methanol reservoir that was filled with dilute methanol and tested at $298 \mathrm{~K}$. Before operation, the MEA needed an activation process to achieve optimal performance. First, deionized water was poured in the methanol reservoir to humidify the MEA, while the cell was kept at $333 \mathrm{~K}$ for $3 \mathrm{~h}$. Second, to activate the catalysts, a $2.0 \mathrm{M}$ methanol solution was fed into the methanol reservoir, while the cell was kept at $333 \mathrm{~K}$. Under these conditions, the cell was operated at $100 \mathrm{~mA}$ for $4 \mathrm{~h}$.

To further investigate the reaction inside the cell, a half-cell measurement was carried out $[23,24]$. A reliable half-cell measurement system requires a reference electrode with a fixed potential and a stable electrical contact. The reference electrode used in this paper was a $2.6 \mathrm{~V} \mathrm{Ag} / \mathrm{AgCl}$ electrode. Figure 6 shows the cathode and anode potentials for the no PF cathode, the full PF cathode, and the partial PF cathode, using a $4 \mathrm{M}$ methanol solution at $298 \mathrm{~K}$. Figure 6a shows that the partial PF cathode, which had its inner and outer layers mixed with the pore forming agent, demonstrated the highest potential. The full PF cathode, which had its whole catalytic layer mixed with the pore forming agent, performed medially. Finally, the no PF cathode, which had no contact with the poreforming agent, had the lowest potential. In all cases, as the discharge current increased, the cathode potential gradually decreased. However, the cathode potential of the partial PF cathode, with the three-layered structure, decreased more slowly than the other two monolayer cathodes. The whole cell voltage is the sum of the potential difference between the anode and cathode. A higher cathode potential or a lower anode potential indicates a smaller electrode polarization, which improves the output voltage and the performance of the cell. Methanol exposure had a definite effect on the cathode potential. Methanol solutions of high concentration can lead to severe methanol permeability; this forms a mixed potential, causing a cathode potential drop and eventually exacerbating cathode polarization. Therefore, the decrease in the cathode potential of the partial PF cathode confirmed that the partial PF cathode increased water back diffusion via a hydraulic pressure gradient, thus reducing methanol crossover. The partial PF cathode enhanced the oxygen mass transport, which also improved cathode potential. Although the methanol crossover of the full PF cathode occurred in a more significant manner than that of the no PF cathode, the cathode potential of the full PF cathode was higher than that of the no PF cathode. This increase in cathode potential was due to the improved oxygen mass transport resulting from the porosity structure of the full PF cathode. 


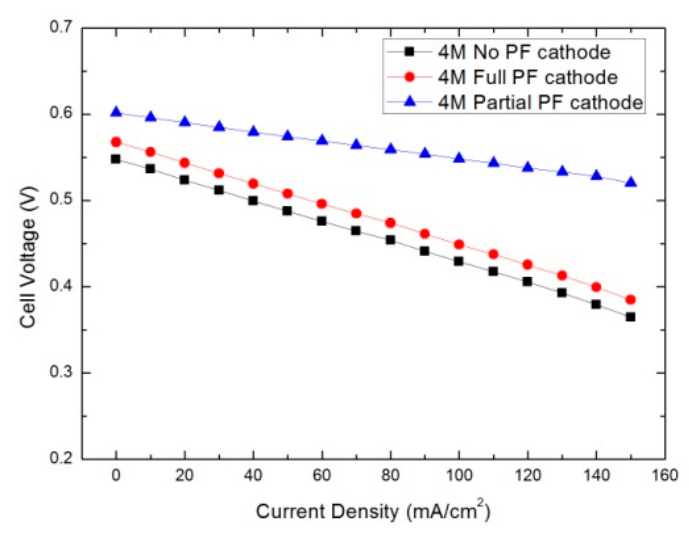

(a)

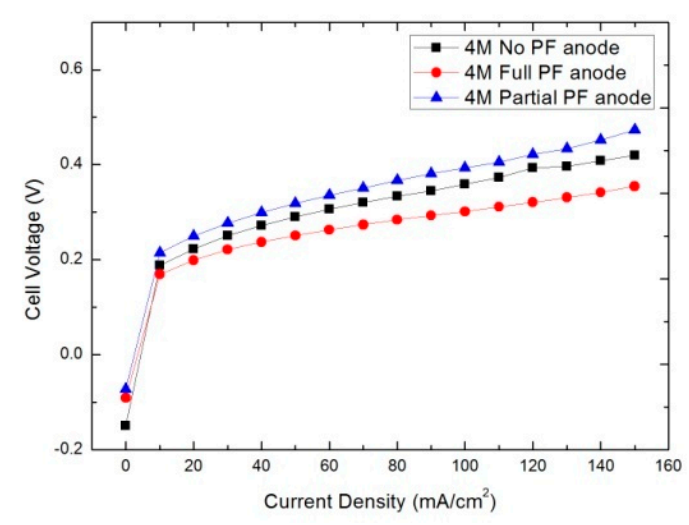

(b)

Figure 6. Cathode and anode potential of no PF cathode, full PF cathode, and partial PF cathode with $4 \mathrm{M}$ methanol solutions at $298 \mathrm{~K}$ : (a) cathode potential; (b) anode potential.

Figure $6 \mathrm{~b}$ shows that the partial PF cathode had a higher anode potential than the other two cathode structures. This can be attributed to the lower temperature of the MEA in the partial PF cathode. The methanol crossover from anode to cathode was directly oxidized by oxygen and released a significant amount of heat. The anode reaction of methanol oxidation had a large activation polarization; however, the methanol crossover generated sufficient heat to decrease the anodic polarization. Therefore, the anodic polarization decreased with methanol crossover. This result suggested that the methanol crossover was reduced in the partial PF cathode by water back diffusion, and that the full PF cathode had the most pronounced methanol crossover.

The performance of cells with three cathodes was measured by the constant current method. Figure 7 shows power density of the no PF cathode, the full PF cathode, and the partial PF cathode operating with 2 and $4 \mathrm{M}$ methanol solutions at $298 \mathrm{~K}$. It can be seen from the curve that the partial PF cathode had the best cell performance, the full PF cathode performed medially, and the no PF cathode had the poorest performance. When the discharge current increased, the differences in performance became more pronounced. When using the $2 \mathrm{M}$ methanol solution, the partial PF cathode, discharged at an $80 \mathrm{~mA} / \mathrm{cm}^{2}$ current density, reached a maximum power density of $22 \mathrm{mWcm}^{-2}$, while the peak power densities of the full PF cathode and the no PF cathode were only 17 and $15 \mathrm{mWcm}^{-2}$, respectively. When operating using the $4 \mathrm{M}$ methanol solution, the maximal power densities decreased to 19,12 , and $9 \mathrm{mWcm}^{-2}$, respectively. This is probably due to the increase in the methanol solution concentration, leading to the conclusion that methanol permeability is critical to performance. Therefore, the cathode polarization phenomenon was significant, and the cathode potential decreased, suggesting that the cathode polarization phenomenon causes output performance degradation. Moreover, we observed that the reduced power densities of the full PF cathode and the no PF cathode were much more obvious than that of the partial PF cathode. This proved that in the high concentration methanol solution, the methanol crossover in the partial PF cathode was not a serious detriment to the water back diffusion, while the other two cathodes suffered from severe methanol crossover. Therefore, the passive $\mu$-DMFC of the partial PF cathode had the best performance.

Figure 8 shows the cathode potential of the no PF cathode and the partial PF cathode discharging under $80 \mathrm{~mA} \mathrm{~cm}^{-2}$ with $2 \mathrm{M}$ methanol at $298 \mathrm{~K}$. The total discharge time was $120 \mathrm{~min}$, and data were recorded every $1 \mathrm{~min}$. The partial PF cathode structure caused the cathode potential to stay steady at approximately $0.53-0.55 \mathrm{~V}$. The cathode potential of the no PF cathode began at approximately $0.46 \mathrm{~V}$. As the reaction proceeded, the cathode potential decreased significantly after $100 \mathrm{~min}$ due to the water generated by the reaction not being discharged in time, causing flooding in the cathode. This phenomenon blocked the oxygen mass transportation and exacerbated the cathode polarization, which resulted in a reduction in the cathode potential. Therefore, it can be seen that the trilaminar- 
catalytic layered cathode can prevent flooding in the cathode, thus improving the output performance of the passive $\mu$-DMFC.

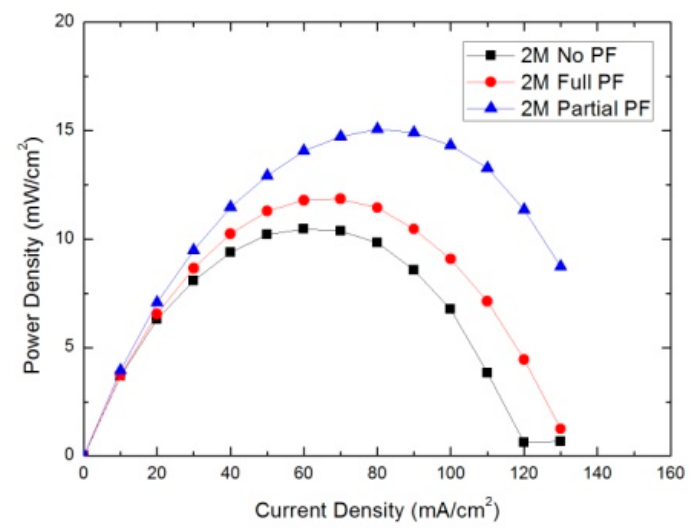

(a)

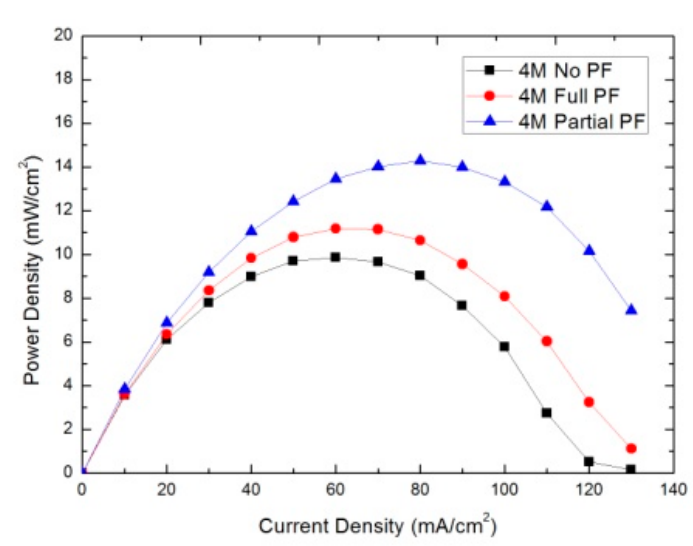

(b)

Figure 7. Power density of the $\mu$-DMFCs with no PF cathode, full PF cathode, and partial PF cathode: (a) 2 M and (b) 4 M methanol solutions.

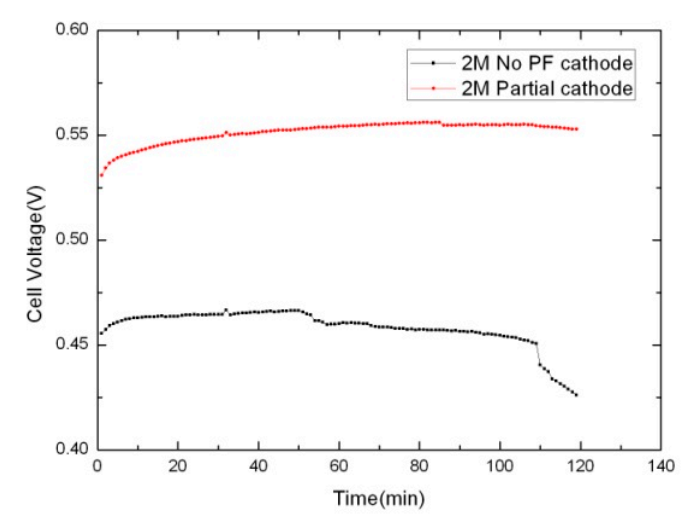

Figure 8. The cathode potential of no PF cathode and partial PF cathode under $80 \mathrm{~mA} \mathrm{~cm}^{-2}$ with $2 \mathrm{M}$ methanol solution.

To ascertain the water back diffusion effect of the trilaminar-catalytic layered cathode, the water transport coefficient was calculated by long-term charging. Table 1 shows the calculated water transport coefficients of the no PF cathode and the partial PF cathode. The water transport coefficient of the no PF cathode was 1.56, while the water transport coefficient of the partial PF cathode was less, only 1.05. The differences in the water transportation coefficients prove that the proposed trilaminar-catalytic layered cathode structure can effectively reduce the cathode water accumulation and slow down the cathode flooding phenomenon, thereby improving the output performance and stability of the passive $\mu$-DMFC.

Table 1. Water transport coefficient of no PF cathode and partial PF cathode.

\begin{tabular}{ccc}
\hline & No PF & Partial PF \\
\hline Final volume $(\mathrm{mL})$ & 1.90 & 2.00 \\
Final concentration $(w \mathrm{wt} \%)$ & 4.77 & 3.81 \\
Water transport coefficient $\alpha$ & 1.56 & 1.05 \\
\hline
\end{tabular}

\section{Conclusions}

A passive $\mu$-DMFC with a novel trilaminar-catalytic layered cathode performed better than one with a traditional catalyst layer due to the porosity gradient created in the trilaminar-catalytic layer. This gradient improved water back diffusion and oxygen mass 
transportation, both of which improved the overall $\mu$-DMFC performance and enabled the partial PF cathode to obtain the optimal performance of 27 and $22 \mathrm{mWcm}^{-2}$ at the concentrations of $2 \mathrm{M}$ and $4 \mathrm{M}$ methanol, respectively. This performance is higher than the no PF cathode and full PF cathode. The water back diffusion effect reduced methanol crossover and flooding in the cathode, which increased the cathode potential. Compared with the no PF cathode, the partial PF cathode structure was more stable, as the cathode potential remained steady at approximately $0.53-0.55 \mathrm{~V}$ and discharged under $80 \mathrm{~mA} \mathrm{~cm}^{-2}$ with $2 \mathrm{M}$ methanol at $298 \mathrm{~K}$. In addition, the water transfer coefficient of the partial PF cathode was 1.05, lower than that of the no PF cathode at 1.56, which also proves that the novel trilaminar-catalytic layered cathode effectively reduces cathode water accumulation and slows the cathode flooding phenomenon.

Author Contributions: Conceptualization, H.D. and J.Z.; methodology, H.D. and Y.Z.; validation and investigation, H.D.; data curation, J.Z.; writing - review and editing, H.D. and J.Z. All authors have read and agreed to the published version of the manuscript.

Funding: This research was funded by National Natural Science Foundation of China (No. 51975023).

Data Availability Statement: Not applicable.

Conflicts of Interest: The authors declare no conflict of interest.

\section{References}

1. Chen, X.; Li, T.; Shen, J.; Hu, Z. From structures, packaging to application: A system-level review for micro direct methanol fuel cell. Renew. Sustain. Energy Rev. 2017, 80, 669-678. [CrossRef]

2. Wang, Y.; Ruiz Diaz, D.F.; Chen, K.S.; Wang, Z.; Adroher, X.C. Materials, technological status, and fundamentals of PEM fuel cells-A review. Mater. Today 2020, 32, 178-203. [CrossRef]

3. Wilberforce, T.; El-Hassan, Z.; Khatib, F.N.; Al Makky, A.; Baroutaji, A.; Carton, J.G.; Olabi, A.G. Developments of electric cars and fuel cell hydrogen electric cars. Int. J. Hydrog. Energy 2017, 42, 25695-25734. [CrossRef]

4. Barbera, O.; Stassi, A.; Sebastian, D.; Bonde, J.L.; Giacoppo, G.; D’Urso, C.; Baglio, V.; Aricò, A.S. Simple and functional direct methanol fuel cell stack designs for application in portable and auxiliary power units. Int. J. Hydrog. Energy 2016, 41, 12320-12329. [CrossRef]

5. Goor, M.; Menkin, S.; Peled, E. High power direct methanol fuel cell for mobility and portable applications. Int. J. Hydrog. Energy 2019, 44, 3138-3143. [CrossRef]

6. Fang, S.; Zhang, Y.; Zou, Y.; Sang, S.; Liu, X. Structural design and analysis of a passive DMFC supplied with concentrated methanol solution. Energy 2017, 128, 50-61. [CrossRef]

7. Wang, L.; He, M.; Hu, Y.; Zhang, Y.; Liu, X.; Wang, G. A “4-cell” modular passive DMFC (direct methanol fuel cell) stack forportable applications. Energy 2015, 82, 229-235. [CrossRef]

8. Carneiro, L.P.T.; Ferreira, N.S.; Tavares, A.P.M.; Pinto, A.M.F.R.; Sales, M.G.F. A passive direct methanol fuel cell as transducer of an electrochemical sensor, applied to the detection of carcinoembryonic antigen. Biosens. Bioelectron. 2020, 175, 112877. [CrossRef]

9. Xia, Z.; Zhang, X.; Sun, H.; Wang, S.; Sun, G. Recent advances in multi-scale design and construction of materials for direct methanol fuel cells. Nano Energy 2019, 65, 104048. [CrossRef]

10. Lee, K.; Ferekh, S.; Jo, A.; Lee, S.; Ju, H. Effects of hybrid catalyst layer design on methanol and water transport in a direct methanol fuel cell. Electrochim. Acta 2015, 177, 209-216. [CrossRef]

11. Yan, X.H.; Zhao, T.S.; An, L.; Zhao, G.; Zeng, L. A crack-free and super-hydrophobic cathode micro-porous layer for direct methanol fuel cells. Appl. Energy 2015, 138, 331-336. [CrossRef]

12. Yuan, W.; Zhang, X.; Hou, C.; Zhang, Y.; Liu, X. Enhanced water management via the optimization of cathode microporous layer using 3D graphene frameworks for direct methanol fuel cell. J. Power Sources 2020, 451, 227800. [CrossRef]

13. Xue, R.; Zhang, Y.; Liu, X. A novel cathode gas diffusion layer for water management of passive $\mu$-DMFC. Energy 2017, 139, 535-541. [CrossRef]

14. Chen, R.; Zhao, T.S.; Yang, W.W.; Xu, C. Two-dimensional two-phase thermal model for passive direct methanol fuel cells. J. Power Sources 2008, 175, 276-287. [CrossRef]

15. Jung, G.B.; Su, A.; Tu, C.H.; Lin, Y.T.; Weng, F.B.; Chan, S.H. Effects of cathode flow fields on direct methanol fuel cell-simulation study. J. Power Sources 2007, 171, 212-217. [CrossRef]

16. Yuan, Z.; Yang, J.; Li, X.; Wang, S. The micro-scale analysis of the micro direct methanol fuel cell. Energy 2016, 100, 10-17. [CrossRef]

17. Ge, J.; Liu, H. A three-dimensional mathematical model for liquid-fed direct methanol fuel cells. J. Power Sources 2006, 160, 413-421. [CrossRef]

18. Barbir, F. PEM Fuel Cells: Theory and Practice; Academic Press: Cambridge, MA, USA, 2013. 
19. Weber, A.Z.; Newman, J. Effects of Membrane- and Catalyst-layer-thickness Nonuniformities in Polymer-electrolyte Fuel Cells. J. Electrochem. Soc. 2006, 154, B405-B412. [CrossRef]

20. Gatto, I.; Saccà, A.; Baglio, V.; Aricò, A.S.; Oldani, C.; Merlo, L.; Carbone, A. Evaluation of hot pressing parameters on the electrochemical performance of MEAs based on Aquivion ${ }^{\circledR}$ PFSA membranes. J. Energy Chem. 2019, 35, 168-173. [CrossRef]

21. Cannio, M.; Righi, S.; Santangelo, P.E.; Romagnoli, M.; Pedicini, R.; Carbone, A.; Gatto, I. Smart catalyst deposition by 3D printing for Polymer Electrolyte Membrane Fuel Cell manufacturing. Renew. Energy 2021, 163, 414-422. [CrossRef]

22. Kamitani, A.; Morishita, S.; Kotaki, H.; Arscott, S. Miniaturized microDMFC using silicon microsystems techniques: Performances at low fuel flow rates. J. Micromech. Microeng. 2009, 18, 125019. [CrossRef]

23. Yang, S.H.; Chen, C.Y.; Wang, W.J. An impedance study of an operating direct methanol fuel cell. J. Power Sources 2010, 195, 2319-2330. [CrossRef]

24. Hogarth, M.P.; Hards, G.A. Direct methanol fuel cells: Technological advances and further requirements. Platinum Met. Rev. 1996, $40,150-159$. 